\title{
INTRAMEDULLARY NAILING;
}

\author{
Gunshot comminuted femur fractures, experience in a tertiary care hospital at Karachi.
}

Dr. Mohammad Shuaib, Dr. Ghulam Muatafa KK, Dr. Naveed Ahmed, Dr. Mohammed Ishtiyaque

ABSTRACT... Objective: Gunshot comminuted fractures of femoral shaft are complicated fractures to treat in orthopedic practice, resulting in prolonged morbidity and extensive disability. Intramedullary interlocking nail is a well-established operative procedure for the management of this entity. The objective of this study is to find out the healing of gunshot comminuted fracture of shaft of femur treated by interlocking nails. Methodology: This study was conducted at Civil Hospital Karachi during July 2009 to December 2009 .Forty three patients sustaining gunshot comminuted fracture of shaft of femur were selected. All patients then underwent fracture stabilization by locking intramedullary nail. The main outcome measure was fracture healing (i.e. callus formation) on X-ray at six months of follow-up. The SPSS version 13 was applied to the data. Results: Majority of the patients (46.5\%) were between 18-30 years of age group with mean age of $36.05(+12.53)$ years. Males were affected more than females with male to female ratio being 4.3:1. Healing (i.e. callus formation) was achieved in 39(90.7\%) patients radiographically at the end of six-months. Conclusions: Intramedullary interlocking nail is safe and effective procedure in the management of gunshot comminuted fractures of femur shaft as it is associated with good healing.

Key words: Comminuted fracture, Femur, Intramedullary nail, Gunshot.

Article Citation

Shuaib M, Mustafa KKG, Ahmed N, Ishtiyaque M. Intramedullary nailing; gunshot comminuted femur fractures, experience in a tertiary care hospital at Karachi. Professional Med J 2013;20(6): 1010-1013.

\section{INTRODUCTION}

Gunshot injuries are major problems worldwide and have a great impact on health budget and economy ${ }^{1}$. Extremities are the most frequently involved sites in gun shot injuries, lower limbs being more involved as compared to upper limbs². Gunshots result in extensive comminution at the fracture site thus making treatment a difficult task ${ }^{3}$. According to Gustilo and Anderson classification, gunshot fractures are type of open fractures and placed in gustilo type $1 \mathrm{II}^{4}$. These fractures are usually managed surgically and stabilized either externally or with internal implants. Plating is associated with increased risk of infection and non-union, ${ }^{4}$ while external fixation is coupled with increased risk of malunion, non-union and pin tract infection. Treatment of femur diaphyseal fractures has been revolutionized after the introduction of intramedullary nailing ${ }^{6}$. These have been associated with relatively lower risk of infection and non-union while better healing proportion as compared to other devices ${ }^{7}$. Intramedullary nailing provides excellent stability against axial and rotational deformation of the fracture. It requires small surgical exposure thus decreasing the risk of infection, easy dressing and early rehabilitation ${ }^{8}$.

Gunshot comminuted femur fractures have been treated with locked intramedullary nailing, however there is limited data available in local literature regarding healing of these fractures. The rationale of this study was to study the results of our patients managed with this technique.

\section{METHODOLOGY}

This study was conducted at Civil Hospital Karachi during July 2009 to December 2009. All the patients, 18 years and above presenting in emergency department with isolated gunshot femur fracture (Gustillo type IIla) were included. Patients with Gustillo type IIIb and IIIc, diabetic patients and patients with multiple gunshot injuries were excluded. Patients were examined in the emergency department and assessed for entry and exit wounds. Patients were diagnosed with anteroposterior and lateral $\mathrm{x}$-rays. All the patients were started on intravenous antibiotics for 5 days after tetanus prophylaxis. Wounds were irrigated in the emergency room and debridement was done in operation theatre within 8 hours of presentation. 
Patients were operated for intramedullary nailing on the next available trauma list by senior consultant. Patients were mobilized on the next day and discharged after 2-3 days. Stitches were removed after 2 weeks and then followed on monthly basis with $x$-rays. Final was assessed in the clinic at six months.

The data was analyzed by using SPSS (version 13; SPSS Incorporated, Chicago, Illinois, USA). Frequencies and percentages were used to summarize categorical variables like gender distribution, postoperative follow-up (i.e. callus formation present/absent) and final outcome (i.e. healing yes/no). Moreover, male to female ratio was also determined. Mean \pm standard deviation (SD) were computed for numerical variables like age distribution. Stratification with regards to age, gender, postoperative follow-up and final outcome was done to control the effect modifiers. Any inferential test of significance was not applicable for this descriptive type case series.

\section{RESULTS}

Between July 2009 to December 2009, 43 patients sustaining isolated gunshot femur fracture were included in this study. Mean (+ SD) age was 36.05 $(+12.53)$ years (Range 18 to 60 years).Thirty-five $(81.4 \%)$ patients in this study were male whereas eight (18.6\%) were female. Male to female ratio was 4.3: 1. Callus was observed radiographically in 39(90.7\%) patients at the end of six months of follow-up. However, in $4(9.3 \%)$ patients, callus was not demonstrated on radiography. Hence, healing was achieved in $90.7 \%$ of cases after intramedullary locking nail usage in gunshot comminuted fracture shaft of femur.

\section{DISCUSSION}

In our study callus formation was observed in 39 patients at the end of six months. Hence, healing rate was observed in $90.7 \%$ of cases after usage of locked intramedullary nail in gunshot comminuted fracture shaft of femur.
Gunshot comminuted fractures of femur shaft are high energy open fracture by definition. They are generally considered to affect young patients as previously mentioned by Moran et al in their case series ${ }^{10}$. In this study, majority of the afflicted patients were between 18 to 30 years of age group with mean age being 36.05 years. Umeret al $\mathbf{l}^{7}$ noticed average age of 36 years in their case series, which is comparable to results of this study. The sex ratio distribution in this study was also in keeping with other reports ${ }^{6}$ and further emphasizes the greater vulnerability of males to trauma. Males in our population play major holding financial matters of family and for that they have to remain outside of their homes most of the time, predisposing to trauma. In this study, $81.4 \%$ of male sustained gunshot comminuted fracture of femur shaft.

Intramedullary nails are weight sharing implants which permit immediate weight bearing after static locking even in unstable fractures. They have the advantage of providing greater fatigue strength, better stability in all planes specially if locking screws are used and providing reamed bone at the fracture site ${ }^{11}$. Therefore, locked intramedullary nail fixation has become the standard of treatment for comminuted femur shaft fracture with reported union rates between 88$97 \%^{12,13}$.

Fogarty and Yeates ${ }^{14}$ retrospectively evaluated 45 patients with 46 femoral shaft fractures treated with interlocking intramedullary nail. The type of fractures included 4 compound and 13 comminuted. The union rate was $98 \%$ with this technique in their series.

Ali and associates ${ }^{15}$ prospectively evaluated a role of intramedullary interlocking nail in 68 patients sustaining femoral fractures as a consequence of high velocity gunshot injuries. They observed overall satisfactory outcome in $88.33 \%$ (61.76\% excellent and $26.47 \%$ good) of cases. Non-union was noticed in $4(5.88 \%)$ patients. Hence, they concluded that intramedullary locked nail is best option for the 
management of femoral shaft fractures due to high velocity gunshot injuries.

Grosse and colleagues ${ }^{3}$ managed 115 open femur shaft fractures by meticulous wound care followed by intramedullary nailing. Healing was noticed in all patients. Therefore, recommended early intramedullary nailing in open femur shaft fractures.

Tuzuner and co-workers ${ }^{16}$ reported $100 \%$ union rates in 42 patients having open femoral shaft fractures. Similarly, Yilmaz et $\mathrm{al}^{17}$ also experienced high union rates with intramedullary interlocking nail in type II and IIIA open fracture of femur shaft.

There were certain limitations to our study including small sample size.

\section{CONCLUSIONS}

In summary, intramedullary interlocking nail is safe and effective technique for management of gunshot comminuted fractures of femoral shaft, as it is associated with excellent healing rates. This facilitates the early return to physical activity of patient.

Copyright@ 20 Aug, 2013.

\section{REFERENCES}

1. Dougherty PJ, Najibi S, Silverton C, Vaidya R. Gunshot wounds: epidemiology, wound ballistics, and softtissue treatment. Instr Course Lect 2009;58:131-9.

2. Udosen AM, Etiuma AU, Ugare GA, Bassey 00 . Gunshot injuries in Calabar, Nigeria: an indication of increasing societal violence and police brutality. Afr Health Sci 2006;6:170-2.

3. Grosse A, Christie J, Taglang G, Court-Brown C, McQueen M. Open adult femoral shaft fracture treated by early intramedullary nailing. J Bone Joint Surg Br 1993;75:562-5.

4. Giannoudis PV, Papakostidis C, Roberts C. A review of the management of open fractures of the tibia and femur. J Bone Joint Surg Br 2006;88:281-9.

5. Ramseier LE, Janicki JA, Weir S, Narayanan UG.
Femoral fractures in adolescents: a comparison of four methods of fixation. $J$ Bone Joint Surg Am 2010;92:1122-9.

6. Gupta A. Dynamic compression nail: a preliminary report. BMC MusculoskeletDisord 2001;2:6.

7. Umer M, Niazi AK, Hussain D, Ahmad M. Treatment of acute fractures of the Femoral Shaft with reamed Intramedullary Interlocking AO Nails. J Pak Med Assoc 2004;54:423-7.

8. Brumback RJ, Toal TR Jr, Murphy-Zane MS, Novak VP, Belkoff SM. Immediate weight-bearing after treatment of a comminuted fracture of the femoral shaft with a statically locked intramedullary nail. $J$ Bone Joint Surg Am 1999;81:1538-44.

9. Burg A, Nachum G, Salai M, Haviv B, Heller S, Velkes S, et al. Treating civilian gunshot wounds to the extremities in a level 1 trauma center: our experience and recommendations. Isr Med Assoc J 2009;11:54651.

10. Moran CG, Gibson MJ, Cross AT. Intramedullary locking nails for femoral shaft fractures in elderly patients. J Bone Joint Surg Br 1990;72:19-22.

11. Beaty JH, Austin SM, Warner WC, Canale ST, Nichols L. Interlocking intramedullary nailing of femoral-shaft fractures in adolescents: preliminary results and complications. J PediatrOrthop 1994;14:178-83.

12. Nowotarski PJ, Turen CH, Brumback RJ, Scarboro JM. Conversion of external fixation to intramedullary nailing for fractures of the shaft of the femur in multiply injured patients. J Bone Joint Surg Am 2000;82:781-8.

13. Bhandari M, Guyatt GH, Khera V, Kulkarni AV, Sprague $S$, Schemitsch EH. Operative management of lower extremity fractures in patients with head injuries. ClinOrthopRelatRes 2003;(407):187-98.

14. Fogarty $A B$, Yeates $H A$. Intramedullary locking femoral nails. Experience with the $\mathbf{A O}$ nail. Ulster Med J 1991;60:129-36.

15. Ali MA, Hussain SA, Khan MS. Evaluation of results of interlocking nails in femur fractures due to high velocity gunshot injuries. J Ayub Med Coll Abbottabad 
2008;20:16-9.

16. Tüzüner T, Subasi M, Kapukaya A, Necmio lu NS. [Treatment of femoral shaft fractures with interlocking intramedullary nailing]. ActaOrthop TraumatolTurc 2002;36:211-9.

\section{AUTHOR(S):}

1. DR. MOHAMMAD SHUAIB

2. DR. GHULAM MUATAFA KK

3. DR. NAVEED AHMED

4. Dr. Mohammed Ishtiyaque
17. Yilmaz E, Karakurt L, Bulut M, Belhan O, Serin E. [Treatment of femoral shaft fractures and pseudoarthrosis with compressive and interlocking intramedullary nailing]. ActaOrthopTraumatolTurc 2005;39:7-15.

\section{PREVIOUS RELATED STUDIES}

Mansoor llyas, Mohammad Idress, Siafuddin Tareen, INTERLOCKED INTRAMEDULLARY NAILING OF LONG BONES. (Original) Prof Med Jour 15(4) 449-454 Oct, Nov, Dec, 2008.

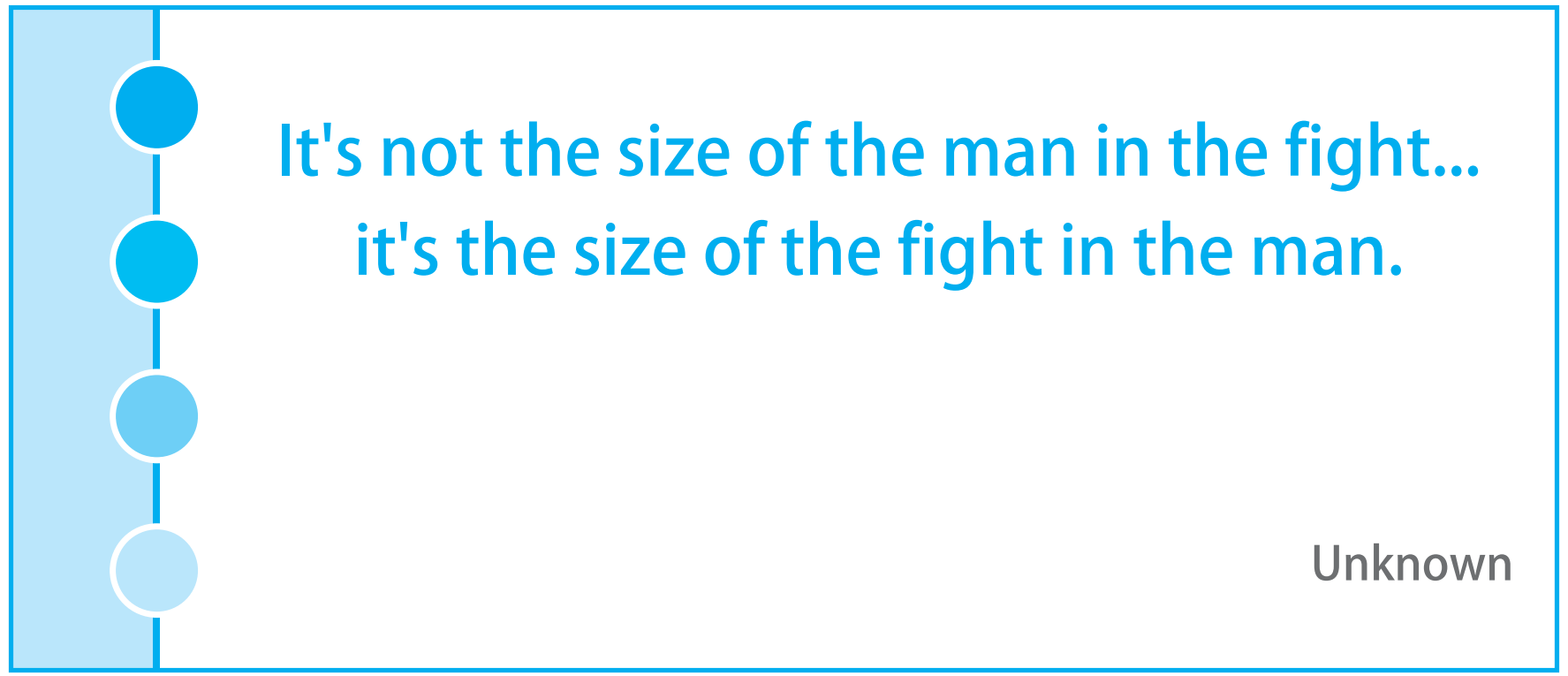

